\title{
Effects of Heat Stress on Reproduction and Survival Rate of Wistar Rats
}

\author{
Abu $\mathrm{MS}^{1}$, Yakubu $\mathrm{OE}^{1, *}$, Udeh $\mathrm{SMC}^{2}$, Imadojemu $\mathrm{OG}^{1}$, and Ogar $\mathrm{RA}^{1}$ \\ ${ }^{1}$ Department of Biochemistry, Federal University Wukari, Nigeria \\ ${ }^{2}$ Department of Biochemistry, Faculty of Biological Sciences, University of Nigeria Nsukka, Nigeria
}

*Corresponding author: Yakubu OE, Department of Biochemistry, Federal University Wukari, Nigeria, Tel: +2348069078726; E-mail: oj4real_2007@yahoo.co.uk

Received: 22 Apr, 2020 | Accepted: 07 May, 2020 | Published: 15 May, 2020

Citation: Abu MS, Yakubu OE, Udeh SMC, Imadojemu OG, Ogar RA (2020) Effects of Heat Stress on Reproduction and Survival Rate of Wistar Rats. J Biochem Analyt Stud 4(2): dx.doi.org/10.16966/2576-5833.122

Copyright: (C) 2020 Abu MS, et al. This is an open-access article distributed under the terms of the Creative Commons Attribution License, which permits unrestricted use, distribution, and reproduction in any medium, provided the original author and source are credited.

\begin{abstract}
Background and objective: Rats were first used for experimental purposes in the mid-18 ${ }^{\text {th }}$ century. The availability of these rats and their survival rate for experimental purposes has been a major challenge throughout most research institutes and universities across Nigeria.

Materials and methods: Twenty albino rats were separated in twos (male and female) into ten (10) groups. Each couple was allowed access to composite feed (1:1 vital feed and maize husk) and clean tap water ad libitum for 21 weeks. The different temperature conditions of the weather as well as the body weight of the animals, birth rate and death rate were monitored and computed averagely.

Results: The temperature was numerically lower in the month of December $\left(25.6^{\circ} \mathrm{C}\right)$ and higher in March $\left(32.4^{\circ} \mathrm{C}\right)$. However, there was a progressive increase in the average temperature from December through April.The highest body weight was recorded in December (156.4 g) and subsequently falls as reproduction begins showing strong linear negative correlation (0.5884) between body weight and temperature. In another case, December and January recorded more births, $4.6 \%$ and $3.8 \%$ rates respectively; however, it dropped to $1.2 \%$ in April giving an overall indication of a weak linear negative correlation (0.3812) between birth rate temperatures. On the other hand, the death rate showed a strong positive correlation (0.9402) between the death rate and temperature.
\end{abstract}

Conclusion: It was evident from the results that, increased temperature generates heat stress that was capable to depreciate the survival and reproductive rates of albino rats.

Keywords: Heat stress; Temperature; Birth rate; Death rate; Wistar rats

\section{Introduction}

Rats are recognized as suitable models in numerous scientific researches in diverse fields including enzymology, parasitology, cardiology, tetralogy, neurology, pharmacology, oncology, immunology and toxicology $[1,2]$. It is estimated that about 15 million rats are being used for various researches in the United States per annum while 11 million are being in Europe with Japan and Canada using speculated values of 5 million and 2 million per annum respectively for the same purpose. Among the rodents family, rats are the most used animals for in vivo experimental purposes accounting for approximately $20 \%$ of the total number of mammals used for scientific researches [3]. In 1906, the Wistar Institute developed the Wistar rat model (Rattus norvegicus) which belongs to the order Rodentia and family Muridae [2]. This rat has stunted hair, a long tail, rounded upright ears, bulge eyes, a pointed snout as well as long whisker (vibrissae) and five toes on each foot with poor eyesight and depends on facial vibrissae and olfaction for sensory evaluation and lack gall bladder [4].
It has been shown that heat stress can also increase adrenal gland weight and reduces pituitary, testis and seminal vesicle weights in rats and consequently decreased spermatozoa count and cause male infertility [5,6]. Arancibia et al. [7]. Found a decrease in prenatal healthy follicles and appearance of a new population of follicles after 2 weeks of heat stress while formation of follicular cysts a long side increased plasma hormone levels, irregular oestrus cycle and decreased ovulation in female rats were evident $[8,9]$.

The availability of these rats and their survival rate for experimental purposes has been a major challenge throughout most research institutes and universities across Nigeria. Hence, it is imperative to carefully evaluate the suitable season to rear these animals for maximum reproductive activity considering the fact that Nigeria is located at tropical region of the globe where temperature can significantly generate heat stress in the animals that could possibly result into traumatic effect on the reproductive cycles as well as the survival rate of the new born. 


\section{Materials and Methods}

\section{Materials}

Cages, Vital Feed, Maize Husk, Feeding Bottles, Plates, Bowl, Saw Dust, Thermometer, Analytical Weighing Balance.

\section{Experimental design}

Fertile Wistar albino rats of reproductive age of both sexes were purchased from Cross River University of Technology (CRUTECH) and transported to the animal house of the Department of Biochemistry, Federal University Wukari, Taraba-Nigeria. They were separated in twos (male and female) into ten (10) groups. Each couple was allowed access to composite feed (1:1 vital feed and maize husk) and tap water ad libitum for 21 weeks and to interact socially throughout the experimental period that spans through different weather conditions of varying temperatures. The temperature condition of the weather as well as the animals' weight, birth rate and death rate were weekly monitored after which the average monthly values were calculated at the end of the experimental period.

\section{Feed formulation and administration}

Grower mash obtained from Vital Feed Company, Jos-Plateau state and maize husks obtained from a local milling company in WukariTaraba, state were mixed thoroughly in the ratio of $1: 1$. The animals were fed daily such that the feed supply does not run short throughout the experimental period.

\section{Measurement of temperature}

Using thermometer, the daily temperature was recorded in degree Celsius $\left({ }^{\circ} \mathrm{C}\right)$. The average monthly temperature was then computed in order to compare the variations of temperature across the months of the experimentation.

\section{Estimation of birth rate}

The birth rate was estimated using the following formula:

$$
\frac{\text { no of births }}{\text { total population }} \times 100
$$

\section{Estimation of death rate}

The death rate was estimated using the following formula:

$$
\frac{\text { noof deaths }}{\text { total population }} \times 100 \%
$$

\section{Data analysis}

The mean values $(n=5)$ and standard error of means of the data obtained were computed and the results were represented in bar charts and scatter diagram plots using MS-Excel.

\section{Results}

\section{Effects of heat stress on reproduction and survival rate on Wistar rats}

Figure 1 shows the average monthly temperature recorded over the experimental period that spans December through April. The temperature was numerically lower in the month of December $\left(25.6^{\circ} \mathrm{C}\right)$ and higher in March $\left(32.4^{\circ} \mathrm{C}\right)$. However, there was a progressive increase in the average temperature from December through April as seen in the chart.
The weight of the animal reduced drastically as the temperature increases as depicted in figure 2 . The highest weight was recorded at the beginning of the experiment in the month of December (156.4 g) and subsequently falls as reproduction begins with increase in the temperature. This result was also collaborated in figure 3 that showed a relatively strong linear negative correlation $(0.5884)$ between weight and temperature.

The birth rate falls with the increase in the temperature as shown in figure 4 . The months of December and January recorded more births, $4.6 \%$ and $3.8 \%$ rates respectively. However, it was noticed that the birth rate was dropped to $1.2 \%$ in April. Consequently, there was a relatively mild linear negative correlation $(0.3812)$ between the birth rate and temperature as presented in figure 5 .

No death was recorded in the months of December and January as compared to February, March and April that recorded deaths in figure 6. It was evident that in March, the death rate was about $5 \%$ which was numerically higher February and April. This result also showed a strong negative correlation (0.9402) between the death rate and temperature in figure 7.

\section{Discussion}

The results from this current study showed that the highest average change in temperature was experienced in the month of March $\left(32.4^{\circ} \mathrm{C}\right)$. The temperature increased progressively from December through March, but drops in the month of April to $29.0^{\circ} \mathrm{C}$. The lowest

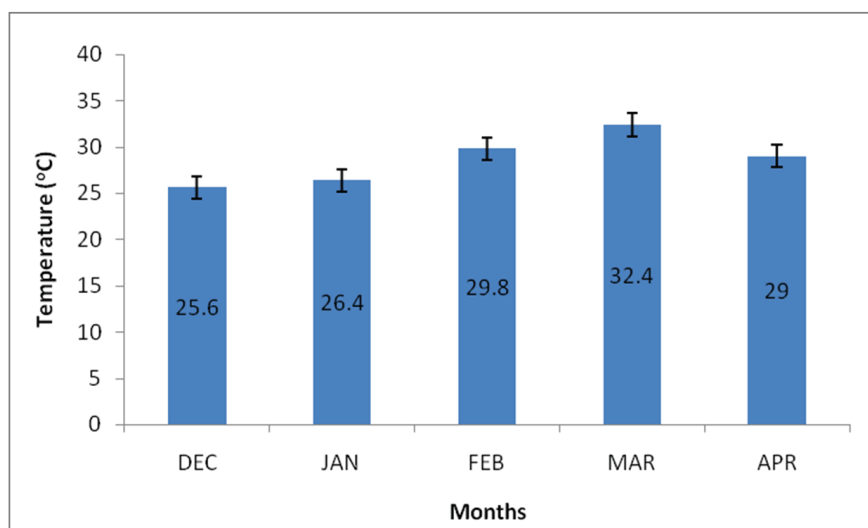

Figure 1: Average monthly temperature recorded during the experimental period.

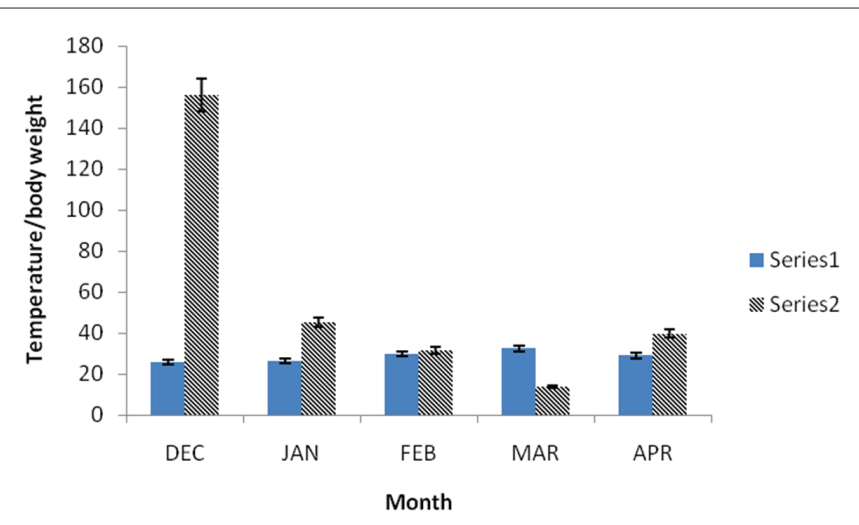

Figure 2: Effect of temperature on average body weight of Wistar albino rats.

Series1: Temperature; Series2: Weight gain 

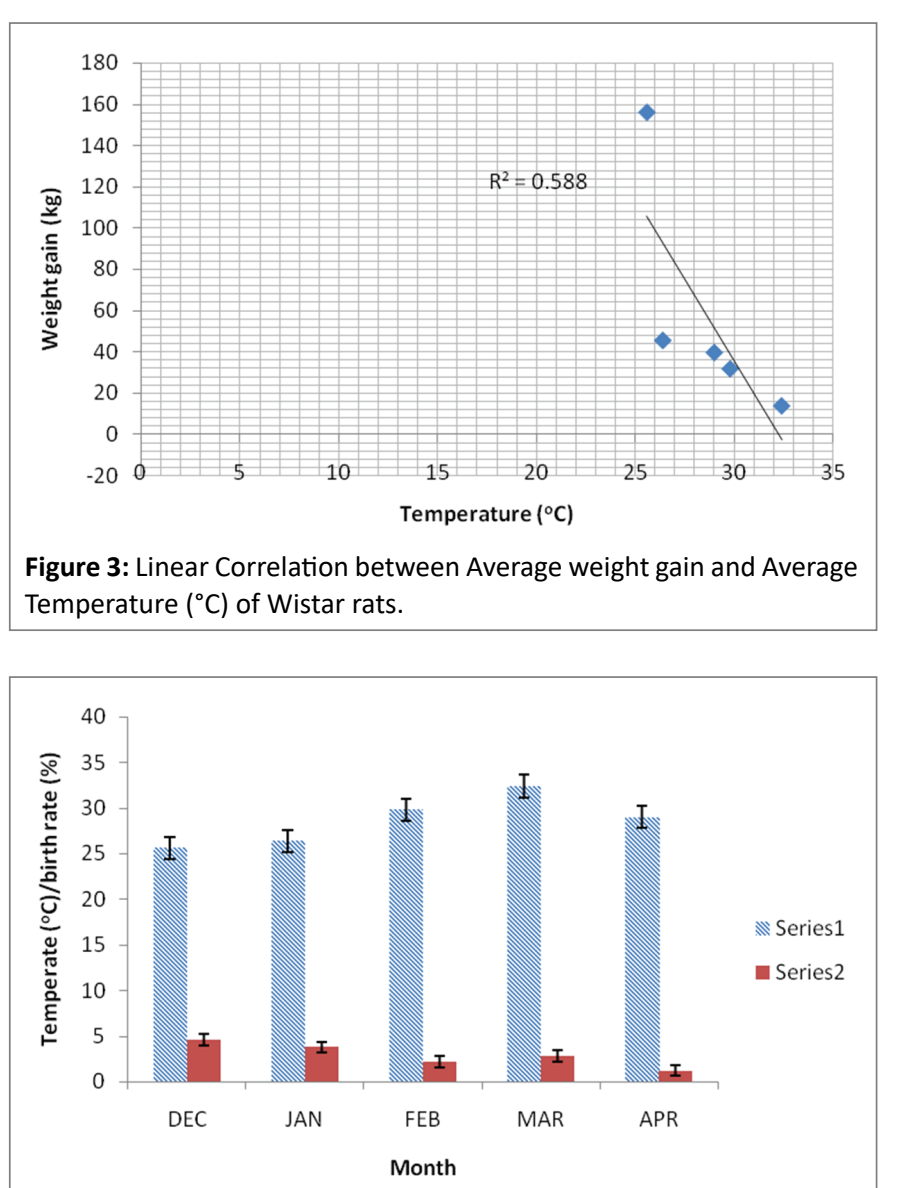

Figure 4: Effect of temperature on average birth rate of Wistar albino rats.

Series1: Temperature; Series2: birth rate

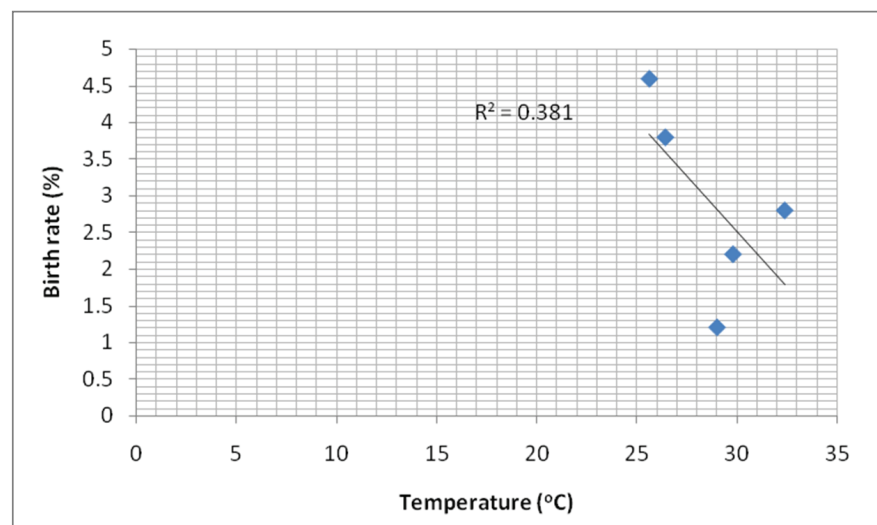

Figure 5: Linear Correlation between Average Birth rate and Average Temperature $\left({ }^{\circ} \mathrm{C}\right)$ of Wistar rats.

average temperature among the months under consideration was recorded in December $\left(25.6^{\circ} \mathrm{C}\right)$. It was observed that the average body weight depreciates appreciably with increase in temperature with the lowest body recorded in March that has the highest temperature. Also, the average birth rate across the months indicates that the animals had the lowest birth rate in April (1.2\%) while the highest birth rate was indicated in December (4.6\%) followed by January (3.8\%). It was recorded that the average death rate across the months indicates that the animals had the highest death rate in March (5.0\%) followed by

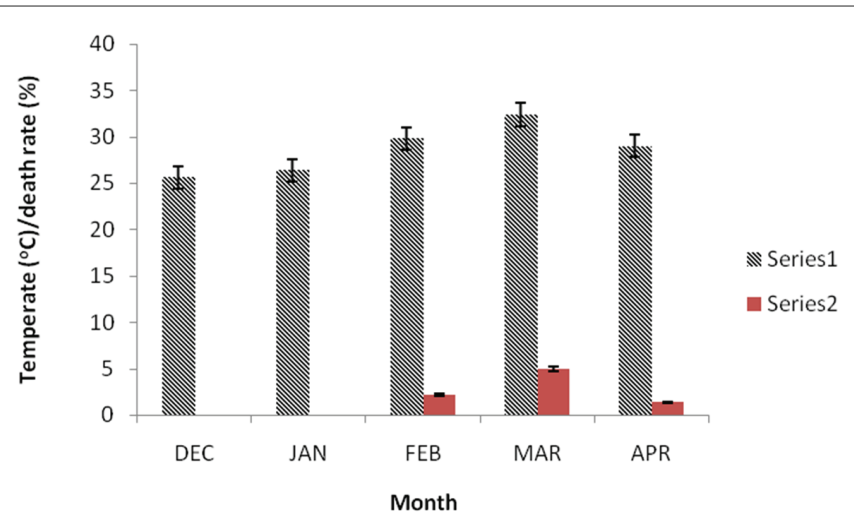

Figure 6: Linear Correlation between Average Birth rate and Average Temperature $\left({ }^{\circ} \mathrm{C}\right)$ of Wistar rats.

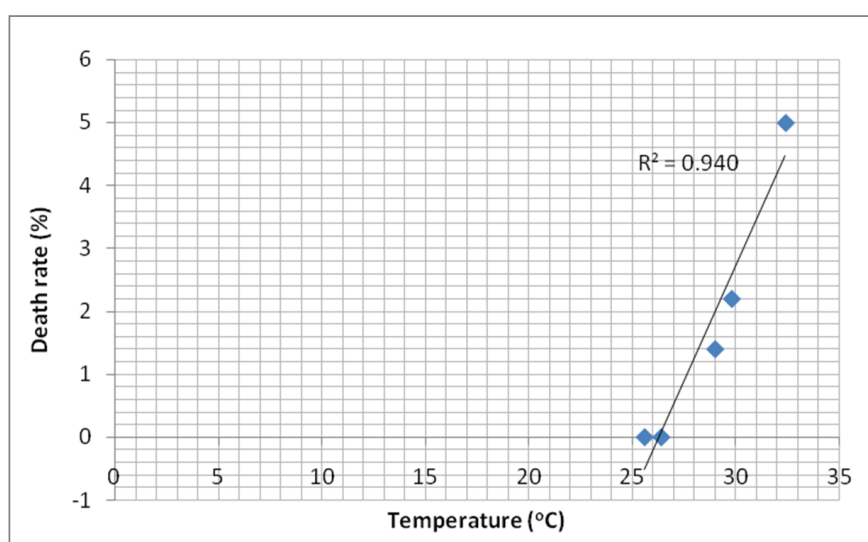

Figure 7: Linear Correlation between Average Death Rate and Average Temperature $\left({ }^{\circ} \mathrm{C}\right)$ of Wistar rats.

February (2.2\%) and April (1.4\%) respectively, while there was no death recorded in December and January respectively. The death rate showed a strong positive linear correlation with the temperature, as the temperature increases, the death rate also increases as well.

Hot temperature increases energy expenditure and in the present study, the decrease in body weight induced by heat stress in rats coincides with the previous study where Rowe EA, et al. [10] noticed significant reduction in body weight of rats after four weeks of heat stress exposure. In addition, the release of corticotropin-releasing hormone often triggered by heat stress can affect food appetite in rats which could as well amount to weight loss owe to low or no food intake [11].

Stress is a basic or perceived threat to the stable homeostasis of an organism [12,13] that could lead to alteration in endocrine and reproductive functions as well as the central and peripheral systems [14]. The decrease in the birth rate as the temperature increases in this present work may be a direct confirmation of the documented effects of heat stress on the reproductive cycles and structures of animals $[9,6]$. There was a negative linear correlation between the birth rate and the average temperature which implies a general reduction in the total number of new born. This change in the birth rate orchestrated by the change in temperature also indicated how biological system can respond to external factors/stimuli.

Heat stress is a condition that drives the body temperature of an organism above set-point temperature and when this temperature is 
exceeded by few degrees, death of the organism usually occurs due to the disruptions of membrane fluidity, protein structure, electrolytes and fluid content [15]. The death rate in this present study was significantly increased as the temperature increase probably due to heat stress. The rise in the temperature above the tolerable threshold of the animals could have resulted to distortion in the composition of biological macromolecules and ions responsible for the death recorded in the months of February, March and April whereas, the no death recorded in December and January could be ascribed to the tendency of the animals to comfortably maintain their homeostasis within the set-point temperature and hence there was no cellular disruptions owe to heat stress, thus; the no death recorded.

\section{Conclusion}

In this present study, the temperature varies considerably across the months and was able to generate heat stress when it was raised above set-point value. Consequently, the heat stress caused reductionin the birth rate and greatly increased the death rate of the animals. Similarly, the body weights of the animals were greatly reduced as the temperature rise across the months.

\section{Significance Statement}

This study reveals that heat stress has a linear correlation with body weight, birth rate and death rate of Wistar albino rats. It has also created awareness as to which period is more suitable for rearing of Wistar albino rats for maximum reproductive activities as well as for experimentation.

\section{Acknowledgement}

The authors would want to appreciate everyone who contributed to the development of this research work.

\section{Authors' Contribution}

Yakubu OE: Designed the work and carried out the experiment.

Imadojemu OG: Carried out the analysis and interpretation of the data.

Abu MS: Supervised the work.

Udeh SMC: Reviewed the manuscript.

Ogar RA: Participated in the laboratory work.

Note: All Authors made financial contribution to the manuscript.

\section{Conflict of Interest}

The Authors declared no conflict of interest.

\section{References}

1. Krinke GJ (2000) The handbook of experimental animals: The laboratory rat. In: Bullock G, Bunton TE, editors. New York: Academic Press.

2. Sengupta P (2013) Environmental and occupational exposure of metals and their role in male reproductive functions. Drug Chem Toxicol 36: 353-368.

3. Fagundes Djalma José, Taha Murched Omar (2004) Choices criteria and current animal specimens. Acta Cirurgica Brasileira 19: 59-65.

4. Gordon CJ (2004) Effect of cage bedding on temperature regulation and metabolism of group-housed female mice. Comp Med 54: 6368.

5. Habib KE, Gold PW, Chrousos GP (2001) Neuroendocrinology of stress. Endocrinol Metab Clin North Am 30: 695-728.

6. Retana-Márquez S, Vigueras-Villaseñor RM, Juárez- Rojas L, AragónMartínez A, Torres GR (2014) Sexual behavior attenuates the effects of chronic stress in body weight, testes, sexual accessory glands, and plasma testosterone in male rats. Horm Behav 66: 766-778.

7. Dorfman M, Arancibia S, Fiedler JL, Lara HE (2003) Chronic intermittent cold stress activates ovarian sympathetic nerves and modifies ovarian follicular development in the rat. Biol Reprod 68: 2038-2043.

8. Denison ME, Zarrow MX (1995) Changes in estrous Cycle of Rat during Prolonged Exposure to Cold. Proc Soc Exp Biol Med 89: 632634.

9. Bernuci MP, Szawka RE, Helena CV, Leite CM, Lara HE, et al. (2008) Locus coeruleus mediates cold stress-induced polycystic ovary in rats. Endocrinology 149: 2907-2916.

10. Rowe EA, Rolls BJ (1982) Effects of environmental temperature on dietary obesity and growth in rats. Physiol Behav 28: 219-226.

11. Satyanarayana $U$ and Chakrapani $U$ (2010) Essentials of Biochemistry. $3^{\text {rd }}$ edition, Books and Allied Limited, India 340-400.

12. Chrousos GP (2009) Stress and disorders of the stress system. Nat Rev Endocrinol 5: 374-381.

13. Herman JP (2013) Neural control of chronic stress adaptation. Front Behav Neurosci 7: 61.

14. Chovatiya R, Medzhitov R (2014) Stress, inflammation, and defense of homeostasis. Mol Cell 24: 281-288.

15. Jardine DS (2007) Heat illness and heat stroke. Pediatr Rev 28: 249258. 